\title{
Analysis on Energy Efficiency and Optimality of LED and Photovoltaic Based Street Lighting System
}

\author{
Chandana S. Kulasooriyage, Satish S. Namasivayam and Lanka Udawatta
}

Abstract: This study evaluates the optimality and energy efficiency of Light Emitting Diode (LED) and Photovoltaic based street lighting systems as a part of energy conservation. This evaluation is based on the detailed review carried out through a country wide street lamp survey.

Since LEDs are becoming increasingly competitive due to their rapidly increasing efficiencies and decreasing cost, this research assessed the LED fixtures which have the capability of achieving $50 \%$ to $70 \%$ energy saving potential compared to the existing established technologies based street lamps available in the country. As a case study, illumination levels were examined at two neighbouring traffic junctions in the Capital City, from Bambalapitiya junction to Kollupitiya junction. Two kinds of measurements were taken and average luminance levels were analysed for all measured points in the traffic lanes. It was found that same lighting performance could be achieved by replacing 250W HPS (High Pressure Sodium) by 150W HPS and further it was verified the same results while having 62\% energy saving by replacing 250WHPS lamps with 111W LED through a simulation with Lighting Reality ${ }^{\mathrm{TM}}$ software. This change would easily meet the minimum recommended level of 7.5 Lux and average luminance of $0.5 \mathrm{~cd} / \mathrm{m}^{2}$ as per British Standards.

Even though solar powered street lighting systems need high capital outlay, it will be one of the most appropriate energy solutions for a country like Sri Lanka. Incentive program development by the government may further encourage LED street lamp and solar powered system development adoptions. This study also recommends that any such incentive program should include performance standards that consider warranty, efficacy and other important criteria as the next steps.

Keywords: Street lighting, Luminance metrics, Light Emitting Diode, Solar panels, Energy efficiency.

\section{Introduction}

Street lighting is an essential public service that provides a safer environment at night time to motorists as well as pedestrians. Proper use of street lighting as an operative tool provides economic and social benefits to the public. The electrical energy consumption of street lighting constitutes an important part of total energy consumption. Saving energy in street lamps is therefore important for total energy savings.

Reductions in energy consumption through the installation of modern lighting

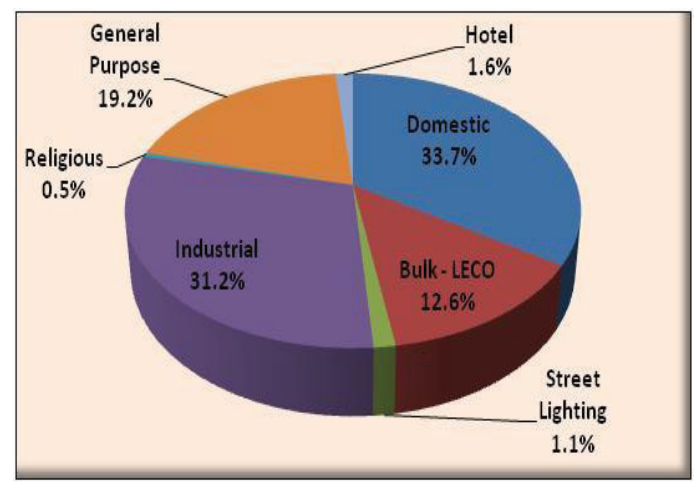

Figure 1 - Annual Electricity

Consumption in Year 2011 equipment, control and management practices have a direct impact on the level of greenhouse gas emissions from street lighting. Reductions in greenhouse gas emissions are directly related to reductions in energy consumption; hence the potential savings are of the same order and vice versa.

\section{Annual Electricity consumption in Sri Lanka}

Ceylon Electricity Board (CEB) issues a Statistical Digest in each year and it indicates the energy statistics in the particular year.

Eng. Chandana S. Kulasooriyage, M.Sc. Eng. (Moratuwa), MIE(Sri Lanka), MIIE(Sri Lanka),

GCGI(UK), C.Eng.,

I. Eng., Electrical Engineer, Ceylon Electricity Board.

Dr. Satish S. Namasivayam, B.Sc.(Hons)(Colombo), M.Phil.(Colombo), FilLic (Uppsala) Ph.D. (Uppsala), M.B.A (Colombo), Department of Electrical Engineering, University of Moratuwa.

Dr. Lanka Udawatta, B.Sc. Eng. (Moratuwa), M.Sc. (Saito), PhD. (Saito), Faculty of Mechatronics Engineering, Higher Colleges of Technology, UAE. 
This is the official publication to expose the energy data to the public. Statistical data published by CEB for annual electricity consumption in Sri Lanka - 2011 is shown in Figure 1.

Even though the percentage value of street lighting energy consumption is $1.1 \%$, its energy wastage is fairly accountable since frequent complaints have been made by the public and state media that the street lamps are continuously burning in daytime at various places in the country. Even though control and operational work of the street lamps are done by local authorities, electricity bills for energy consumption has been levied by CEB in accordance with pre - prepared estimates since the energy meters have not fitted in each and every street lamp. While there is no mechanism to update that estimates and new installations is being done frequently, a large amount of revenue supposed to be gained by CEB is not received annually. But, even updated data base for the street lamps and its accessories are also not available in controlling authorities or power utilities in Sri Lanka. Therefore, it was an utmost requirement to conduct a street lamp census island wide.

\section{The Street Lamp Census}

A street lamp census has been carried out by the CEB in all over the country, in between late February 2010 and mid May 2010. A monitoring team from each province was formed with an Officer in Charge of each team to carry out the census accurately

By the results of the census it was found that a majority of street lamps used in the country are mercury vapour lamps and its percentage is $34.2 \%$. Even though these lamps are considered to be having a long lifetime by reputed manufacturers, most of the local authorities use very cheap products and as a result, lamp replacements are counted frequently in their maintenance records. The $2^{\text {nd }}$ highest percentage goes to CFL. Since they also give a low intensity, these lamps are suitable for by-roads. Being their life span is between 8000 - 10000 hours, they also should be replaced frequently [2]. Hence, their maintenance cost tends to be higher. The $3^{\text {rd }}$ highest percentage goes to fluorescent lamps. This type of lamps with low wattages, which are also fitted along by-roads, need to be replaced frequently because it has lower life span, and further, the ballast consumes a considerable amount of power. Although the percentage of incandescent lamps is $8.5 \%$, the number of lamps is 33,024 , so that the power loss is the highest. The percentage of sodium vapour lamps is $4.3 \%$ and these are having higher efficiency and longer life span.

According to the street lamp survey, some of the roads and streets are not properly lit by street lamps but in some streets, specially in Colombo city, it has been found that some roads are over lit. Hence an illumination measurement program has been implemented by the CEB to understand the Lux level appearing on some major roads.

\section{Case Study}

Improvement of the Galle road from Kollupitiya junction to Bambalapitiya junction as a model road is the latest project of the Colombo Municipal Council (CMC) which was launched in year 2010 to create a sound road network in the city. An arrangement of the street lamps was done in a diagonally opposing configuration erected on either side of the road to make it a new design and new installation and 250W HPS lamp fixtures were also fitted. As a case study, illumination levels were examined by the CEB, in collaboration with the $\mathrm{CMC}$, to introduce the optimum street lighting system. 
A convenient location to measure the illumination of lamps on the Galle road was selected. After measuring the light intensity of existing 250 W HPS lamps, 4 Nos. of adjacent bulbs with opposite direction were replaced by new 150W HPS lamps to get the illumination comparable with the values of previous ones. 78 measurement points were laid out on a lane marking centers to form as a grid in the monitoring area. Spacing of the grid points of monitored lamp fixtures along the road was $5 \mathrm{~m}$ on alternative sides. The distance between two adjacent grid points was $3.5 \mathrm{~m}$. The Lamp Fixture mounting height goes up to $12 \mathrm{~m}$ above the road surface. Illumination measurements were taken at a height of 6 inches above ground, at around $7.00 \mathrm{pm}$ when natural light from the moon was at a minimum. Two kinds of measurements were taken in this case study. One measurement was taken by switching ON all lamps so that the spacing between lamps was $30 \mathrm{~m}$ and other by switching OFF alternate lamps in the test area in which the spacing was $57 \mathrm{~m}$. Luminance metrics were calculated identically for both fixture spacing $(30 \mathrm{~m}$ and $57 \mathrm{~m})$, and over the entire test area. Average illumination levels were calculated based on all measured points in the traffic lanes by ordinary calculation method [4].

The uniformity of the light provided by the lamp fixtures was measured by three metrics: Coefficient of Variation (CV), also known as measure of the disparity between the actual values of all measured points and the average of those values, Average-to-Minimum Uniformity ratio (AMU), and Maximum-to-Minimum Uniformity ratio (MMU). A lower $\mathrm{CV}$ is indicative of a more uniform distribution and AMU provides an indication of how low the minimum measured level is compared to the average of all measured values.
This indicates that considering all measured points of 250W and 150W HPS lamps with 30m spacing, both have somewhat equal values for AMU and MMU and that tended to provide a more uniform lighting distribution in both cases as shown in the summary of illumination measurement in table 2. Additionally, both cases provide better uniformity in illuminated areas and in the $57 \mathrm{~m}$ spacing case, it gets worse than the $30 \mathrm{~m}$ spacing case. Therefore, it can be concluded that usage of $150 \mathrm{~W}$ HPS is most suitable instead of high powered 250W HPS lamps.

\subsection{LED Street Lamp Technology}

Light Emitting Diodes (LEDs) are the latest technology to appear in the street lighting industry. This technology is popular for its high energy efficiency, maintainability, and flexibility. The more recent LED models can produce over 100 lumens of light per watt and are expected to work above $70 \%$ of their initial light output even after 50,000 hours. Indeed, Haitz's Law predicts that the light output of LEDs increases by a factor of 20 every 10 years, while the cost decreases by a factor of 10 over the same period of time [5]. At the time of this research, LEDs are beginning to be installed in outdoor lighting in most of the countries because of the ability of lamp fixture to provide greater control of light dispersion and greater maintenance savings compared to traditional sources.

\subsection{Street lighting design using computer simulation method}

Most importantly, the design of street lighting system must be appropriate for respective roads $\&$ streets and should provide the sufficient level of illumination (Lux level) and uniformity of light specified in the reputed street lighting standards such as BS EN 13201and IESNA Standard Grid RP-8.

Table 2 - Summary of illumination measurements

\begin{tabular}{lccc}
\hline & $\begin{array}{c}\text { 250W HPS } \\
\text { (57m spacing) }\end{array}$ & $\begin{array}{c}\text { 250W HPS } \\
\text { (30m spacing) }\end{array}$ & $\begin{array}{c}\text { 150W HPS } \\
\text { (30m spacing) }\end{array}$ \\
\hline Average & 26.70 & 45.60 & 16.60 \\
Maximum & 57.00 & 67.00 & 30.00 \\
Minimum & 3.90 & 21.00 & 8.00 \\
Average/Minimum (AMU) & 6.80 & 2.20 & 2.10 \\
Maximum/Minimum (MMU) & 14.60 & 3.20 & 3.80 \\
Standard Deviation & 16.11 & 11.05 & 6.95 \\
Coefficient of Variation (CV) & 0.60 & 0.24 & 0.42 \\
\hline
\end{tabular}


These design decisions should be based on meeting of local lighting requirements while achieving maximum energy efficiency. An optimization methodology through computer simulation tool named Lighting Reality (LR) software has been applied in this study to identify optimal lamp type and wattage for the existing lamp positions in Galle road section. Street lamp design is subjected to meet specific horizontal illumination uniformity and luminance requirements according to guidance published by international standards [6]. Therefore, actual figures were further verified by comparing with simulation values arrived by using Lighting Reality software, which offers the key benefits of enabling the design of lighting schemes with a wide selection of lighting manufacturers' products, and of conforming to all major international standards including IES Standard Grid RP-8 and BS EN 13201 Standard [7,8]. A modal layout of Lighting Reality Pro software is shown in Figure 2.
Hence, suitable LED was reviewed from the manufacturer's database in LR software to verify whether it is compatible with selected standards. Therefore, LED and HPS lamp fixture were chosen to compare light intensity distribution along the selected Galle road section for both $30 \mathrm{~m} \& 57 \mathrm{~m}$ lamp spacing in opposite configuration. British Standards (BS EN 13201), recommend the overall uniformity $\left(\mathrm{U}_{0}\right)$ and longitudinal uniformity $\left(\mathrm{U}_{1}\right)$ measured at the road surface as $0.35 \mathrm{~cd} / \mathrm{m}^{2}$ and $0.40 \mathrm{~cd} / \mathrm{m}^{2}$ respectively for vehicular roads like Galle road (ME5) [6]. In order to achieve even greater energy savings, CMC could substitute $111 \mathrm{~W}$ LED fixtures for the 250W HPS lamps as investigated above by comparing Philips - City soul LED (ECO113-28/740, 11300 lm, cool white) and GE lighting HPS lamp (LU250/XO/T/40, $33000 \mathrm{~lm}$ )by simulation results of Lighting Reality software as shown in Figure $3 \& 4$. One can expect to see the same luminance at all points by having $62 \%$ of energy saving $[9,10]$.

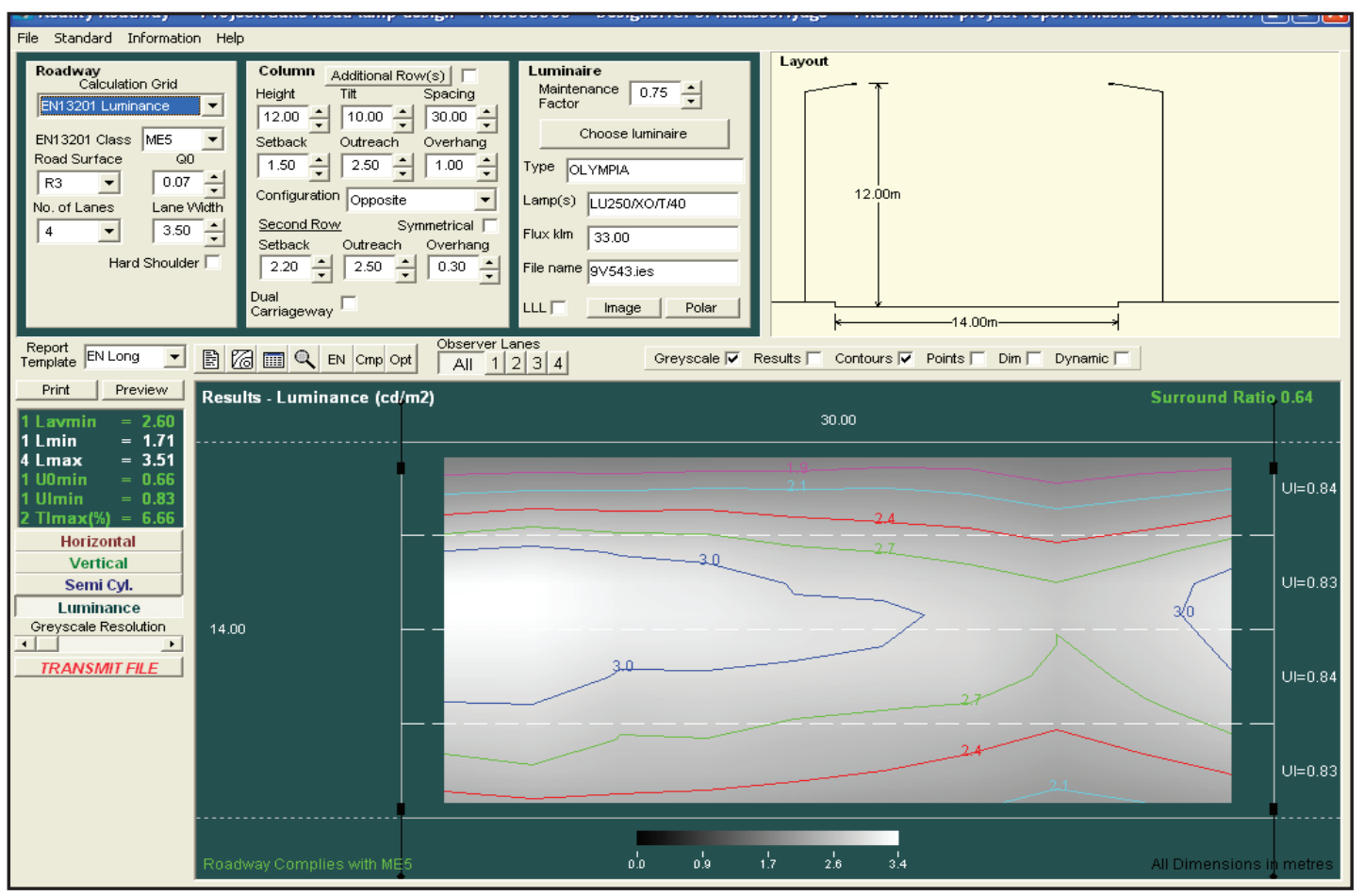

Figure 2 - Modal layout of Lighting Reality Pro software

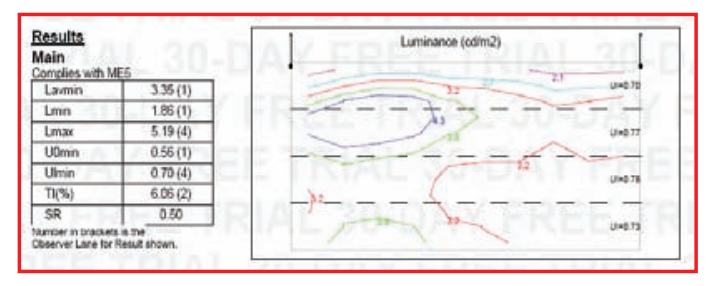

Figure 3 - Simulation results for luminance measurement for GE lighting 250W HPS lamp

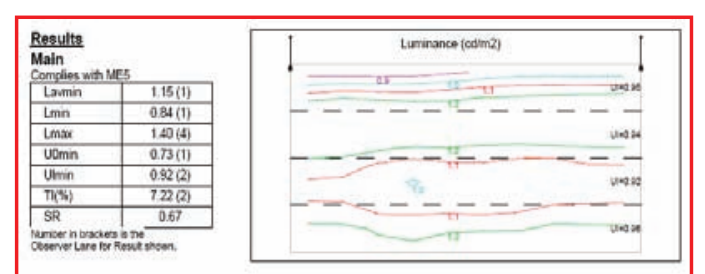

Figure 4 - Simulation results for luminance measurement for Philips 111W LED fixture 


\subsection{Luminance calculation}

The road luminance and illumination measurements are critical parameters that affect the quality of road lighting. Those should be measured in the field and analysed in driver's perspectives. In the case study, Lighting Reality software simulation was verified with selected Galle road section illumination measurements to provide sufficient comparative studies between expected values and actual values.

The British Standards and IESNA Standards recommend a minimum illumination of 7.5 Lux measured at the road surface for ME5 class vehicular roads. In this design, Galle road was classified as ME5 class road having road surface classification of R3. Table 3 gives the comparison of simulated values with actual by $250 \mathrm{~W}$ HPS lamp replacement with $111 W$ LED lamp which were used in opposite configuration in the said section.

Since the existing lamp post spacing cannot be altered, selection of street lamps have been done by evaluation of simulated \& actual luminance measurements in lighting design of this study. Results outcome by the simulation showed that $111 \mathrm{~W}$ LED is also suitable for $57 \mathrm{~m}$ spacing and it is compatible with standard. But, 250W HPS having $57 \mathrm{~m}$ spacing is not suitable since it is not appropriate for the appearance of road beauty due to low lighting level. The results of illumination shows that 250W HPS lamps are in overdesign according to the BS standards and 150W HPS lamps are good enough to cater the standards. Those actual and simulated results confirmed that this replacement is acceptable for energy efficient - street lighting system.

\section{Economic Analysis in Case studies}

This research includes two case studies;

1. Island wide survey of available existing street lamps and
2. Measurement of luminance level of existing HPS lamps fixed in Galle road section

3. LED lamp is the kind of recently developed energy efficient lamp in new generation and it has special features such as dimming facilities, long life and continuous technology improvement. Hence in this research, existing lamps replacement by equivalent LED was selected as the best option. The selection criterion is indicated in Table 4. Estimated life spans of existing lamps are extracted from Energy efficient Street lighting guidelines-USAID, India - 2010 [12].

The manufacturers of high powered SSL type white LED fixtures supplied to various countries predict the life span of the LEDs used in the fixture ranging from 50,000 to over 100,000 hours (roughly 12 to 24 years at 4380 hours per year). But the life span assessed in this research was taken as 50,000 hours which is the lowest value that manufacturer's claimed. It was assumed that LED fixtures would still require some level of maintenance costs and periodic routine visits for cleaning, inspection, control circuit repair, and so forth. Additionally, as a fixture consists of multiple components (LEDs, driver, housing, coating, etc.), the expected useful life of the fixture may not be the same as that of the LEDs alone.

Due to the lack of unified international technical standards and product specifications, there are many kinds of LED lighting products. Hence, broken lights and drivers should generally be replaced as a whole, resulting in maintenance difficulties and rising costs. However the luminous efficiency of LED street lamps has been increasing yearly and prices are falling. Therefore, this study discusses the investment value of LED street lamps at the present market value

Table 3 - Comparison of illumination (lux) measurement [ME5 Road class]

\begin{tabular}{|c|c|c|c|c|c|c|c|c|}
\hline \multirow{3}{*}{$\begin{array}{l}\text { Lamp type } \\
\text { Spacing (m) }\end{array}$} & \multicolumn{3}{|c|}{ Actual } & \multicolumn{4}{|c|}{ Simulated } & \multirow{3}{*}{$\begin{array}{c}\text { Standard } \\
\text { value }\end{array}$} \\
\hline & \multicolumn{2}{|c|}{ 250W HPS } & \multirow{2}{*}{$\begin{array}{c}\begin{array}{c}150 W \\
\text { HPS }\end{array} \\
30\end{array}$} & \multicolumn{2}{|c|}{ 250W HPS } & \multicolumn{2}{|c|}{ 111W LED } & \\
\hline & 57 & 30 & & 57 & 30 & 57 & 30 & \\
\hline Average & 26.70 & 45.60 & 16.60 & 28.30 & 53.76 & 9.81 & 18.64 & 7.5(min.) \\
\hline Maximum & 57.00 & 67.00 & 30.00 & 55.77 & 70.91 & 18.64 & 23.02 & - \\
\hline Minimum & 3.90 & 21.00 & 8.00 & 8.98 & 30.15 & 4.47 & 13.36 & 7.5(min.) \\
\hline Min. / Avg. & 0.15 & 0.46 & 0.48 & 0.32 & 0.56 & 0.46 & 0.72 & 0.4 (min.) \\
\hline Min. /Max. & 0.07 & 0.31 & 0.26 & 0.16 & 0.43 & 0.24 & 0.58 & - \\
\hline $\begin{array}{l}\text { Status with } \\
\text { standard }\end{array}$ & $\begin{array}{c}\text { Not } \\
\text { comply }\end{array}$ & Comply & Comply & $\begin{array}{c}\text { Not } \\
\text { comply }\end{array}$ & Comply & Comply & Comply & \\
\hline
\end{tabular}


Table 4 - Existing lamp replacement by LED

\begin{tabular}{lcccccc}
\hline \multicolumn{1}{c}{ Type of lamp } & $\begin{array}{c}\text { Incandes } \\
\text { cent }\end{array}$ & $\begin{array}{c}\text { Fluores } \\
\text { cent }\end{array}$ & CFL & $\begin{array}{c}\text { Mercury } \\
\text { vapour }\end{array}$ & $\begin{array}{c}\text { Sodium } \\
\text { vapour }\end{array}$ \\
\hline \multirow{2}{*}{ Lamp Details } & Rated Power (W) & 100 & 40 & 23 & 150 & 250 \\
\cline { 2 - 7 } & AverageLife Span (Hrs.) & 1000 & 5000 & 8000 & 5000 & 12000 \\
\hline No of lamp fittings & 33024 & 84825 & 120567 & 133044 & 16635 \\
Lamp input power including ballast (W) & 100 & 60 & 23 & 185 & 295 \\
Replacement LED input power (W) & 15 & 28 & 15 & 75 & 111 \\
Power reduction (\%) & 85 & 53 & 35 & 59 & 62 \\
LED useful life time (hours) & 50000 & 50000 & 50000 & 50000 & 50000 \\
\hline
\end{tabular}

Since the assumed life of the LED fixture is greater than the longest time period considered (12 years), end-of-life replacement costs were not included in this analysis. Fixture replacement frequency was then based on an annualized probability of failure. Annual maintenance costs were calculated based on the probability of fixture failure during and after the warranty period. It was assumed that the cost of replacement for LED fixture failure under warranty would be only labor cost, while cost of replacement after warranty included labor and fixture replacement cost. Life span and failure frequencies of existing lamps were verified by available maintenance recording data received from CMC and several local authorities. The calculations are summarized in Table 5.

In the lamp replacement scenario, the initial investment for existing lamp installation is the lamp fitting cost plus the cost of installation. Since the cost of installation is assumed to be the same for both lamp types, the total incremental cost of installation for LED fixture is the difference in material costs between the
LED fixture and the existing lamp fitting. The resulting Simple Payback Periods and Net Present Value (NPV) are calculated by Discounted Cash Flow (DCF) analysis in the lamp replacement scheme as per lamp basis and it is summarized in Table 6[13].

The payback periods in this particular case study correspond to roughly 50,000 hours of operation and are based on bulk-purchased fixture costs. Individual fixture purchases, or purchases in small numbers, would carry increased lamp fixture cost, and thereby lengthen the simple payback period.

In addition, the calculated simple payback periods are sensitive to estimated maintenance savings, which are in turn highly dependent on the specific installation scenario. As a result of these uncertainties and the noted sensitivity, ranges were calculated for each economic scenario considered around the estimated annual maintenance savings.

Table 5 - Annual maintenance cost calculation of LED fixtures

\begin{tabular}{|c|c|c|c|c|c|}
\hline \multicolumn{6}{|l|}{ Existing street lamps } \\
\hline & Incandescent & Fluorescent & CFL & $\begin{array}{l}\text { Mercury } \\
\text { Vapour }\end{array}$ & $\begin{array}{l}\text { Sodium } \\
\text { vapour }\end{array}$ \\
\hline Watts per lamp including ballast & 100 & 60 & 23 & 185 & 295 \\
\hline Annual energy usage $\quad(\mathrm{kWh})$ & 438.00 & 262.80 & 100.74 & 810.30 & 1292.10 \\
\hline Annual energy cost $\quad$ (Rs) & 8322.00 & 4993.20 & 1914.06 & 15395.70 & 24549.90 \\
\hline Annual maintenance cost (Rs) & 1100.00 & 500.00 & 450.00 & 1000.00 & 1100.00 \\
\hline Avg. annual Lamp cost (Rs) & 950.00 & 450.00 & 1400.00 & 3100.00 & 4300.00 \\
\hline
\end{tabular}

\begin{tabular}{|c|c|c|c|c|c|}
\hline Equivalent LED lamp fixtures & & & & & \\
\hline Watts per lamp fixture & 15 & 28 & 15 & 75 & 111 \\
\hline Annual energy usage $\quad(\mathrm{kWh})$ & 65.70 & 122.64 & 65.70 & 328.50 & 486.18 \\
\hline Annual energy cost & 1248.30 & 2330.16 & 1248.30 & 6241.50 & 9237.42 \\
\hline Annual maintenance cost (Rs) & 650.00 & 450.00 & 650.00 & 550.00 & 750.00 \\
\hline Lamp fixture cost $\quad$ (Rs) & 5000.00 & 7500.00 & 5000.00 & 45000.00 & 65000.00 \\
\hline
\end{tabular}


Table 6 - Lamp replacement economic analysis

\begin{tabular}{lcccc}
\multicolumn{1}{c}{ Type of lamp } & $\begin{array}{c}\text { Incremental } \\
\text { Cost (Rs.) }\end{array}$ & $\begin{array}{c}\text { Total annual } \\
\text { saving (Rs.) }\end{array}$ & $\begin{array}{c}\text { Simple Payback } \\
\text { Period (years) }\end{array}$ & $\begin{array}{c}12-\text { year } \\
\text { NPV (Rs.) }\end{array}$ \\
\hline $\begin{array}{l}\text { Incandescent lamp replacement by } \\
\text { 15W LED lamp }\end{array}$ & 5000.00 & 7523.70 & 0.66 & 51698.36 \\
$\begin{array}{l}\text { Fluorescent lamp replacement by } \\
\text { 28W LED lamp }\end{array}$ & 7500.00 & 2713.04 & 2.76 & 12945.38 \\
$\begin{array}{l}\text { CFL replacement by 15W LED lamp } \\
\text { Mercury vapour lamp replacement by }\end{array}$ & 5000.00 & 465.70 & 10.74 & -1490.05 \\
$\begin{array}{l}\text { 75W LED lamp } \\
\text { Sodium vapour lamp replacement by } \\
\text { 111W LED lamp }\end{array}$ & 65000.00 & 15312.48 & 4.69 & 27376.94 \\
\hline
\end{tabular}

\section{Results}

According to the street lamp survey in 2010, approximately 390000 street lamps in different types were used island wide, consuming $155 \mathrm{GWh} /$ year of electricity and representing $1.55 \%$ of total electricity consumption in Sri Lanka. Energy consumption for street lighting in year 2009 was 108 GWh as per statistics digest of CEB and this shows the percentage increase of street lamp installation could be $30 \%$ annually [15]. Most probably the newly installed street lamps also may be consisting with inefficient technologies; the energy loss will be increased annually and these should be minimized to obtain an energy efficient street lighting system. So, there are three options which are identified to fulfil this ambition, such as:

6.1 Option 1 - Replacement of all existing street lamps by equivalent LED fixtures

Economic performance was evaluated primarily by simple payback of the LED luminaries versus existing street lamps. Considering the calculation results mentioned in Table 6, it was understood that CFL bulb replacement is not economical. DCF analysis (NPV calculation) shows the figure becomes negative and hence it is not recommended to replace existing CFL by LED equivalent to get an energy efficient street lighting system.
However environmentally, CFL disposal effects must be taken into consideration since above evaluation is based only on economic gains. Therefore, except CFL, LED replacement assessed in this option shows significant energy and maintenance savings potential, achieving $40 \%$ to $80 \%$ savings compared to the existing street lamps.

6.2 Option 2 - Replacement of all existing street lamps by solar powered LED lighting system

In this scenario, economic analysis was done for replacing existing street lamps with stand alone solar powered LED lighting systems. The solar energy potential as renewable energy can be selected to power this system so that solar energy in Sri Lanka is highly reliable and available throughout the daytime [17].

Even though, the apparent maintenance cost of standalone system is very low, actual cost may be much higher because system contains rechargeable battery and electronic controller. Other than that, components of standalone system work throughout the day due to electricity accumulation during daytime and discharging it in night time. So, periodic inspection needs to be done, especially on batteries and electronic circuits.

Table 7 - Lamp replacement economics for stand-alone systems

\begin{tabular}{lcccc}
\hline \multicolumn{1}{c}{ Type of lamp } & $\begin{array}{c}\text { Incremental } \\
\text { Cost (Rs.) }\end{array}$ & $\begin{array}{c}\text { Total annual } \\
\text { saving (Rs.) }\end{array}$ & $\begin{array}{c}\text { Simple Payback } \\
\text { Period (years) }\end{array}$ & $\begin{array}{c}12-\text { year } \\
\text { NPV (Rs.) }\end{array}$ \\
\hline $\begin{array}{l}\text { Incandescent lamp replacement by } \\
\text { 15W LED stand along system }\end{array}$ & 175000.00 & 8222.00 & 21.28 & -104156.62 \\
$\begin{array}{l}\text { Fluorescent lamp replacement by } \\
\text { 28W LED stand along system }\end{array}$ & 175000.00 & 4293.20 & 40.76 & -138008.42 \\
$\begin{array}{l}\text { CFL replacement by 15W LED stand } \\
\text { along system }\end{array}$ & 175000.00 & 1164.06 & 150.34 & -164970.09 \\
$\begin{array}{l}\text { Mercury vapour lamp replacement } \\
\text { by 75W LED stand along system }\end{array}$ & 250000.00 & 15195.70 & 16.45 & -119068.99 \\
$\begin{array}{l}\text { Sodium vapour lamp replacement } \\
\text { by 111W LED stand along system }\end{array}$ & 250000.00 & 23869.90 & 10.47 & -44329.30 \\
\hline
\end{tabular}


The prices claimed by manufacturers for stand-alone solar powered system vary with the quality and the durability. Hence maintenance and incremental cost were considered according to the average values of above factors. Hence the resulting simple pay back periods and NPV are calculated for stand-alone system in the same way as done for DCF analysis for the existing lamps. These calculations are summarized in Table 7.

The analysis shows that it is currently uneconomical to integrate a solar powered street lighting system with LED for each existing street lamp. The deployment of such a system increases the payback from 10 years to onwards and hence the incremental energy savings from selected LED lights are insufficient to justify the cost on pure economical basis.

Despite the electrical savings, the present high upfront cost of PV based LED street lighting systems would be a barrier to their current adoption. Somehow, if solar powered technologies were implemented in conjunction with the LED lamps, there would be potential reductions of at least $70 \%$ in $\mathrm{CO}_{2}$ emissions and zero energy costs from national grid for street lighting as compared to traditional technologies.

\subsection{Option 3 - Introduction of proper street lighting control system}

Nowadays a street lighting management system does not properly exist in most of the local authority areas. Therefore commuters can see some lamps alight during the whole daytime. Therefore, the $3^{\text {rd }}$ option consists of street lamp controlling management system by 3 modes of operation such as; photocell switching, timer switching and programmable timer switching for partial night street lighting instead of manual operation. The photocells and timers are freely available in the local market and those can be easily fixed to existing street lamps or LED replacement without any significant modification. Economic analysis was done to verify the energy reduction for street lamps which were counted in the survey and a summary is shown in table 8 .

The research revealed that a street lamp controlling management system also should be implemented by using above discussed three modes. These modes could be taken into practical where the location is suitable for each mode or combine of them.

This research has considered all the above facts and the percentage of energy reduction in each type of existing street lamps which could be converted to equivalent LED technology is shown in Table 9.

Hence, it was realized through this study that it is possible to implement efficient street lighting system by combining automatic lamp controls with LED lamps for existing street lamps except CFL.

\section{Conclusion}

Even though LED usage around the world is becoming matured and competitive, that technology is still rather new to Sri Lanka. Although the manufactures assure a very long life span for LED products, they often provide warranty only for 3 to 5 years. However, it is likely that improvements in production or added requirements could also affect the cost of LED fixtures.

The most challengeable concern to implement above system may be finding the capital cost to initiate the system. Although the costs of the product and installation are ultimately recovered through the energy saving of the street lamps, the local authority would still hesitate to pay for the purchase and installation of the LED street lights. Therefore, an incentive program development by the Government of Sri Lanka (GOSL) may further encourage LED street lamps and standalone solar powered system development adoptions. Nowadays, Urban Development Authority (UDA) has initiated to install solar powered street lighting systems in remote areas which cannot be reached by the existing national power grid as well as in jogging areas where people do exercises.

It was found that proper inventory updating system of street lamps has not been conducted either by local authorities or by CEB. Survey revealed that the expansion of street lamp account would be $30 \%$ annually. Hence an accurate recording system should be implemented. In addition to the replacement of existing lamps by LED equivalents, some street lamps might have been installed for a purpose that no longer exists, or they might be significantly over-or undersized for current needs. Therefore, some methods could be applied to verify the operation and status of the 
Table 8 - Energy saving by different modes of controlling in street lamps

\begin{tabular}{lccc}
\hline \multicolumn{1}{c}{ Mode of operation } & $\begin{array}{c}\text { Daily energy saving } \\
\text { (kWh) }\end{array}$ & $\begin{array}{c}\text { Percentage of } \\
\text { energy saving } \\
\mathbf{( \% )}\end{array}$ & $\begin{array}{c}\text { Simple } \\
\text { Payback Period } \\
\text { (Years) }\end{array}$ \\
\hline Mode 1 - Photocell switching & 83034 & 14.3 & 2.42 \\
Mode 2 - Timer switching & 103793 & 17.9 & 3.75 \\
Mode 3 - Programmable timer switching & 126611 & 21.8 & 1.16 \\
\hline
\end{tabular}

Table 9 - Comparison of energy saving \& $\mathrm{CO}_{2}$ reduction by LED replacement with auto controlling

\begin{tabular}{lrrrr}
\hline \multicolumn{1}{c}{ Parameter } & Incandescent & Fluorescent & $\begin{array}{r}\text { Mercury } \\
\text { Vapour }\end{array}$ & $\begin{array}{r}\text { Sodium } \\
\text { vapour }\end{array}$ \\
\hline No. of lamps installed & 33024 & 84825 & 133044 & 16635 \\
Total watts per lamp & 100 & 60 & 185 & 295 \\
Wattage of equivalent LED & 15 & 28 & 75 & 111 \\
Avg. lifetime of equivalent LED (years) & 11.9 & 11.9 & 11.9 & 11.9 \\
Total annual energy cost saving (Rs.Mn.) & 233.60 & 225.89 & 1217.91 & 254.72 \\
Total annual maintenance cost saving (Rs.Mn.) & 14.86 & 4.24 & 59.87 & 5.82 \\
Total annual cost saving(Rs.Mn.) & 248.46 & 230.13 & 1277.78 & 260.54 \\
Total cost saving during lifetime of LED(Rs.Mn.) & 2956.71 & 2738.59 & 15205.60 & 3100.49 \\
Percentage of total saving(\%) & 79.85 & 49.39 & 58.58 & 61.06 \\
Reduction of CO emission (ton) & 4917.9 & 4755.6 & 25640.2 & 5362.6 \\
\hline
\end{tabular}

street lighting system by electronically tracking and reporting using modern database system such as Geographical Information System (GIS). As initial step, all parties involved in the LED upgrades need to get an accurate inventory of the street lights installed in the system, and to correct any mistakes. A Centralized Management System (CMS) can also provide the capability to control LEDs individually, by streets, and by zone, to dim, performance monitor and reprogram LED fixtures individually as well as to provide the central node to other current or future city infrastructure. This is one effective way to increase the energy savings and bill savings from the upgrades.

\section{References}

[1] CEB Report, Statistical Digest - 2010, Statistical Unit, General Manager's branch, 2011.

[2] Clinton Climate Initiative, Outdoor Lighting Program, pp 11-12.

[3] LED Street Light Research Project, Pittsburgh, pp. 22, September 2011.
[4] Morante, P., "Mesopic Street Lighting Demonstration and Evaluation Final Report", Lighting Research Center, pp 27-32, 2008.

[5] Jackson, M., "Research Report: LED Lighting", Woodside Capital Partners International, pp 310, 2012.

[6] Lighting Reality software, www.lightingreality.com

[7] British Standards, BS EN 13201 1-4, Road Lighting

[8] American National Standard Practice for Roadway Lighting. ANSI / IESNA RP-8-00, Approved 6/27/2000, P. 8

[9] Philips LED catalogue www.ecat.lighting.philips.com/1/led/function al-lighting/citysoul-led/22412/cat//

[10] Luminaires Catalogue, International Edition 2010/2011, GE Lighting, pp $43-45$.

[11] Douglas Hartley, Cassie Jurgens, Eric Zatcoff, Street light report, "Life cycle assessment of street lighting technologies", University of Pittsburgh, 2009.

[12] Energy Efficient Street Lighting Guidelines, USAID ECO - iii Project, version 2, pp 2-4, 2010 
[13] Herbohn, J., Hattison, S., "Introduction to Discounted Cash Flow Analysis and Financial Functions in Excel", 11(2), pp 111-116

[14] CEB Report, Statistical Digest - 2011, pp 511,Statistical Unit, General Manager's branch, 2012

[15] International Commission in Illumination, CIE publications 140-2000, Technical Report, Road lighting calculations.

[16] Ceylon Electricity Board, Annual Report \& Accounts-2010, System control Branch, pp.55103

[17] Peiris, T. S. G., Thatill, R. O., “An alternative Modal of Solar Radiation", Coconut Research Institute, 26-34, 1994.

[18] Dowling, K., "The Future of LED Lighting", Illumination Engineering Society, 2009.

[19]Highway Lighting, Bureau of design and environment manual, December 2002, 56(2) 56(5).

[20] Energy Efficient Street lighting Guidelines, USAID ECO- iii Project, Version 2, pp 2-4, 2010.

[21] Tichelen, P. V., Geerken, T., Jasen, B., " Public Street Lighting - Final Report", pp 145-149, 2007.

[22] Efficient Street Lighting Design Guide, Lighting Research Center, pp 4-5, 2003.

[23] Roadway Lighting Design manual, Minnesota Department of Transportation, pp 28-34, 2006. 